Ítalo Martins e Cunha iD italocunha.rs@gmail.com Instituto Brasileiro de Educação Continuada INBEC

Francisco Heber Lacerda de Oliveira iD heber@det.ufc.br Universidade Federal do Ceará (UFC)

\section{Comparativo técnico-financeiro entre o método convencional e o uso de lona plástica para proteção contra precipitações em aterros rodoviários}

\section{Technical-financial comparison between the use of the conventional method and the use of plastic tarpaulin to protect against precipitation in landfills}

\section{Comparativo técnico-financiero entre el método convencional y uso de lona plástica para protección contra precipitaciones en nivelaciones de carreteras}

\section{Comparaison technico-financière entre la méthode conventionnelle et l'utilisation d'une toile plastique pour se protéger des précipitations chez les}

\section{Resumo}

Nos processos de implantação rodoviária é importante o conhecimento sobre o índice de precipitação na região, principalmente quando se trabalha com solos plásticos. Suas características exigem um cuidado especial para que a camada atinja a melhor capacidade de suporte possível, pois elevadas taxas de precipitação tendem a atrasar o andamento da obra. A consequência desse fato é a necessidade de mais dias de tratamento de camadas para alcançar a umidade adequada à compactação, aumentando o tempo e o custo de execução dos serviços. Nesse sentido, o presente trabalho comparou, técnica e financeiramente, a proteção de camada de um aterro rodoviário contra precipitações utilizando dois procedimentos distintos: o convencional, denominado selagem de cancha, e outro com aplicação de lona plástica. Concluiu-se que o uso da lona plástica proporciona maior agilidade na execução dos serviços e também ganhos financeiros relacionados à mão de obra, equipamentos e combustível.

Palavras-chave: Aterro chuva. Lona plástica. Rodovia. Solo.

\begin{abstract}
In the process of road implantation it is important to knowabout the precipitations index in the region of services, especially when working with plastic soils. Its characteristics require special care for the layer to achieve the best possible support capacity, as high precipitation rates tend to delay theprogress of the work. The consequence of this fact is the need for more days oftreatment of layers to achieve adequate moisture for compaction, increasing the time and cost. In this sense, the present paper technically and financially compared the layer protection of a road landfill against rainfall using two different procedures: the conventional one, called field sealing, and the other one with application of plastic canvas. It was concluded that the use of plastic canvas provides greater agility in the execution of services and also financial gains related to labor, equipment and fuel.
\end{abstract}

Keywords: Highway. Landfill. Plastic canvas. Rain. Soil. 


\section{Resumen}

En los procesos de construcción de carretera es importante el conocimiento sobre el índice de precipitación en la región de la obra, principalmente cuando se trabaja con suelos plásticos. Sus características exigen un cuidado especial para que la capa alcance la mejor capacidad de soporte posible, porque elevadas tasas de precipitación tienden a retrasar el curso de la obra. La consecuencia de este hecho es la necesidad de más días de tratamiento de capas para alcanzar la humedad adecuada a la compactación, aumentando el tiempo y el coste de la ejecución de los trabajos. En este sentido, la presente investigación comparó, técnica y financieramente, la protección de capa de una nivelación de carretera contra precipitaciones utilizando dos procedimientos distintos: el convencional, denominado sellado de la cancha, y el otro con aplicación de lona plástica. La conclusión es que el uso de la lona plástica proporciona mayor agilidad en la ejecución de la obra y, también, ganancias financieras relacionadas al trabajo, equipos y combustible.

Palabras-clave: Nivelación. Lluvia. Lona plástica. Carretera. Suelo.

\section{Résumé}

Pendant la mise en œuvre des routes, il faut connaître l'indice de précipitation où on fait des travaux, en particulier lors de travaux avec des sols plastiques. Ses caractéristiques nécessitent des précautions particulières pour que la couche atteigne la meilleure capacité de charge possible, car des taux de précipitations élevés ont tendance à ralentir la progression des travaux. Par conséquent, II faut disposer de plusieurs jours de traitement des couches pour obtenir une humidité de compactage adéquate, ce qui augmente le temps et le coût d'exécution des services. En ce sens, le présent travail a comparé, techniquement et financièrement, la protection d'une couche d'un site de décharge face aux précipitations selon deux procédés distincts : le premier est très conventionnel, appelé injection de scellement, et l'autre a été fait avec l'application d'une toile plastique. II a été conclu que l'utilisation de toiles en plastique permet une plus grande souplesse pendant les travaux, bien comme des avantages financiers liés à la main-d'œuvre, à l'équipement et au carburant.

Mots-clés: Site de décharge. Pluie. Toile plastique. Autoroute. Sol.

\section{Introdução}

Segundo Pinto (2006), os solos considerados finos apresentam uma característica chamada coesão, caracterizada por ser a resistência ao cisalhamento que ocorre quando não há atuação de pressão externa no solo. Solos coesivos apresentam coesão verdadeira e possuem resistência à penetração de água, porém, uma vez que a água tenha conseguido penetrar, ela encontra dificuldade de sair do interior da massa de solo. O solo estudado neste trabalho é argiloso e, de acordo com o IPR (2006), entende-se que ele apresenta granulação fina, com grãos de forma lamelar, alongada e tubular. Devido à finura, forma e composição mineral de seus grãos, o comportamento geral das argilas varia sensivelmente com a quantidade de água que envolve seus grãos. Portanto, com determinada umidade, esse tipo de solo apresenta características marcantes de plasticidade. A coesão depende diretamente de seu teor de umidade, pois, quanto menos úmidas, maior a coesão apresentada.

Ainda conforme Pinto (2006), em umidades não muito elevadas, o ar se apresenta em formas de canalículos intercomunicados. A redução do atrito pela água e os canalículos de ar fazem com que a massa específica fique maior com o maior teor de umidade. Entretanto, a partir de certo teor de umidade, o exercício da compactação não consegue mais expulsar o ar dos vazios, pois o solo está saturado e o ar fica cercado por água. Por conseguinte, para uma determinada energia de compactação aplicada, há certo teor de umidade, chamado de umidade ótima, correspondente à massa específica aparente seca máxima. Segundo o DNIT (2009), compactação dos solos consiste na retirada de ar dos seus vazios com o objetivo de aumentar a 
massa específica através de equipamento mecânico ou manual, com isso, ocorre o aumento da resistência e estabilidade do solo.

Nesse contexto, observa-se que existe a necessidade de buscar meios de otimização da etapa de tratamento dos aterros rodoviários executados com material argiloso, deixando o solo menos úmido possível após um dia de chuva, de modo que a umidade ótima seja atingida mais facilmente. Diante do exposto, o objetivo deste trabalho é realizar uma análise técnica e financeira da proteção contra precipitações de camada de aterro rodoviário na Rodovia BR-116/RS utilizando dois procedimentos distintos: o convencional, denominado selagem de cancha, e outro com aplicação de lona plástica. Desse modo, pretende-se identificar qual dos dois métodos apresenta maior eficácia para etapa de tratamento do aterro rodoviário, minimizando a penetração da água das chuvas no solo, diminuindo o tempo de tratamento e, consequentemente, otimizando o serviço de compactação.

\section{Método de pesquisa}

O estudo descrito neste trabalho foi realizado no estado do Rio Grande do Sul, por ocasião da execução do Lote 8 do Projeto de Duplicação da Rodovia BR-116, compreendido entre o km 470,100 e o km 489,000. Conforme o projeto executivo, o material destinado às camadas de aterro é de característica plástica. A comparação ocorreu em dois segmentos experimentais do trecho, além da simulação de aterro rodoviário feita na unidade industrial, ou seja, foram três locais de estudo, a saber: (I) simulação de quatro camadas de

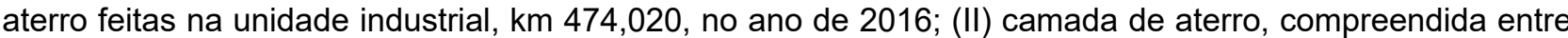
o km 481,460 e o km 481,660, estudada em 2014, mas cabe destacar que em metade desses 200 m houve aplicação da lona plástica e na outra metade não ocorreu aplicação; e (III) aterro de acesso ao Viaduto de Turuçu, localizado entre o km 483,075 e o km 483,166, feito com muro de terra armada. O estudo desse trecho foi feito em 2015 e anteriormente à chuva, sendo a lona aplicada em um lado da obra e não aplicada no outro.

Para monitorar a ocorrência das chuvas, a localização do canteiro de obras do Lote 8 (no km 482,100) foi registrada em uma página eletrônica de previsões, o WindGuru. Trata-se de um serviço especializado que toma como base modelos meteorológicos, permitindo o fornecimento de previsões em qualquer lugar do planeta. Dessa forma, há um controle com maior precisão na decisão de utilização, ou não, do método alternativo de proteção do aterro.

Para verificação da umidade ótima do material, bem como sua massa específica aparente seca máxima, foi realizado o ensaio de compactação de solos (IPR,1994). Também foram realizados os ensaios de consistência (IPR 1994a e 1994b), com o objetivo de verificar o limite de liquidez (LL) e o limite de plasticidade (LP) necessários para a determinação do índice de plasticidade (IP) do solo utilizado e classificá-lo segundo a metodologia do TRB (Transportation Research Board).

Além disso, o teor de umidade do aterro (IPR, 1994c) foi monitorado diariamente, de modo a obter dados que permitissem analisar o desenvolvimento dos dois segmentos (com e sem proteção da lona plástica) e quantificar a média de variação horária do teor de umidade durante o processo de aeração.

Para quantificar os índices de precipitação dos dias estudados, instalou-se um pluviômetro em cada frente de serviço. O estudo foi avaliado em escritório, e os dados foram organizados digitalmente em planilhas eletrônicas para análise dos acréscimos e/ou decréscimos no teor de umidade das duas situações (com e sem lona).

A verificação dos custos decorrentes dos dois métodos foi feita através do Sistema de Custos Referencias de Obras (SICRO) do Departamento Nacional de Infraestrutura de Transportes (DNIT) para a região do Rio Grande do Sul, com data base de outubro de 2018. O SICRO tem como objetivo desenvolver e aplicar de forma contínua uma metodologia eficaz para aferição permanente das composições de custos nos modais aquaviário, rodoviário, ferroviário e terminais, orientando o mercado na direção dos interesses da administração pública, de modo a desestimular a utilização de preços abusivos. 


\section{Estudo comparativo dos aterros rodoviários}

Esta seção apresenta um estudo comparativo de dois sistemas de aterros rodoviários, sendo um com proteção de lona plástica e o outro apenas com a selagem de cancha. Além disso, apresenta a verificação dos custos decorrentes dos dois métodos através do Sistema de Custos Referencias de Obras (DNIT, 2018). Conforme já citado, o estudo foi realizado no Lote 8 do Projeto de Duplicação da BR-116/RS, compreendido entre o $\mathrm{km} \mathrm{470,100} \mathrm{e} \mathrm{o} \mathrm{km} \mathrm{489,000.}$

\subsection{Classificação dos solos estudados}

As duas jazidas que deram origem ao solo de estudo estão localizadas no km 477,380 e no km 481,440, e serão chamadas de 1 e 2, respectivamente. Por meio dos ensaios de caracterização e de acordo com o sistema de classificação do TRB, constatou-se que aj 1 possui um material do tipo A-6 (argiloso) e a jazida 2, do tipo A-2-4 (areia argilosa), ambos com características de material plástico. Um parâmetro fundamental para o desenvolvimento deste estudo é o tempo necessário para diminuir a umidade desses solos através do processo de aeração. Para alcançar um parâmetro fidedigno, optou-se por simular 4 camadas de aterro, mais bem explicadas no decorrer do trabalho.

\subsection{Simulação dos aterros}

Em março de 2016 foi realizada a coleta de materiais oriundos das duas jazidas anteriormente mencionadas. Os solos extraídos são de característica argilosa e de mesma origem dos utilizados no aterro experimental estudado no ano de 2014 e no segmento junto ao muro de terra armada estudado em 2015. Adotou-se esse critério com o intuito de que a simulação ficasse mais próxima de uma situação real possível.

Depois da coleta dos materiais, eles foram levados até o laboratório da unidade industrial e as camadas foram montadas na mesma posição solar dos aterros estudados durante a obra. Foram construídos quatro segmentos (dois em cada material), com dimensões de $1,70 \mathrm{~m} \times 0,80 \mathrm{~m}$, e realizados os ensaios de compactação (IPR,1994), granulometria (ABNT,1984) e limites de Atterberg (IPR 1994a e 1994b). As figuras 1 e 2 demonstram os aterros simulados com o material da jazida 2, utilizado, também, na execução do aterro junto aos muros de terra armada.

Figura 1 - Tijolos junto ao bordo dos aterros.

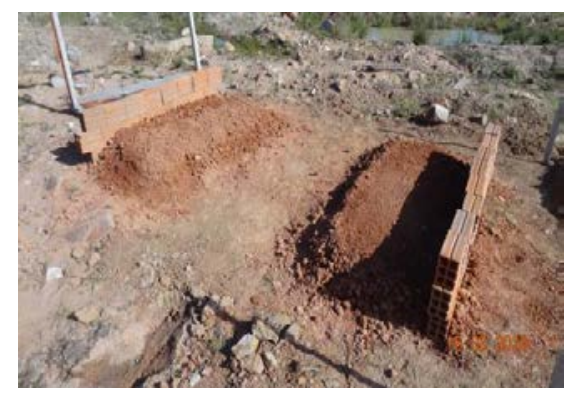

Fonte: Elaborado pelo autor, 2016.
Figura 2 - Material após ser revolvido.

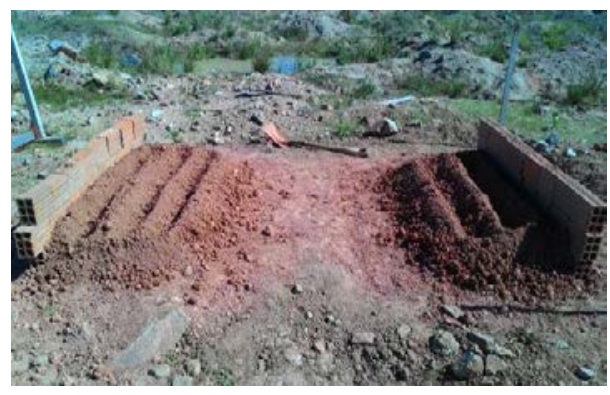

Fonte: Elaborado pelo autor , 2016.

Um dos objetivos da simulação foi quantificar a média da variação horária no teor de umidade do solo depois de aerado. Para essa finalidade, procedeu-se da seguinte forma: (I) umedecimento dos 4 segmentos diariamente, no turno da manhã, com posterior verificação da umidade das duas extremidades e do centro (o teor de umidade utilizado foi a média entre as três coletas); (II) aeração do material uma vez por hora durante o dia; (III) verificação da umidade no final da tarde; e (IV) acompanhamento e análise da variação ocorrida no teor de umidade. Essa situação simula a aeração feita com o arado de disco em um aterro real. Dessa forma, foi possível obter um parâmetro do quanto decresce o teor de umidade dos solos estudados por hora. Além 
disso, os aterros simulados também foram utilizados com um segundo objetivo: comparar os teores de umidade após a chuva sobre os aterros com e sem lona. Através do WindGuru, a previsão de chuva foi monitorada diariamente e, quando verificada a possibilidade iminente de precipitações, a lona plástica foi aplicada. Foram feitas duas simulações de aterro com o material de uma jazida, mantendo um segmento com lona plástica e o outro não. Isto foi feito para o solo extraído da outra jazida, sendo todos os aterros feitos com espessura de 0,20 m. A figura 3 apresenta o croqui dos 4 aterros simulados próximos ao laboratório da unidade industrial.

Figura 3 - Croqui da localização dos quatro experimentos.

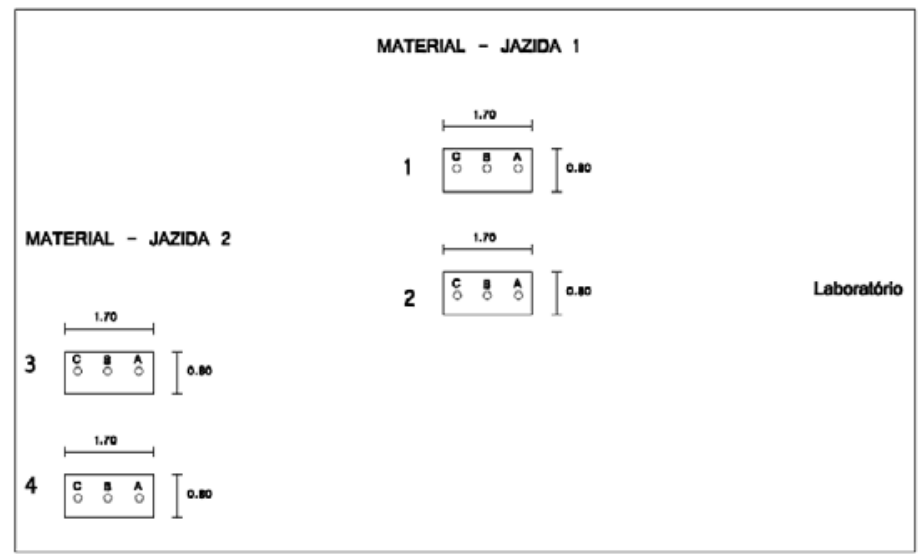

Fonte: Elaborado pelo autor, 2016.

As figuras 4, 5 e 6 demonstram a simulação dos aterros com e sem lona plástica com material da jazida 1 e da jazida 2 e o procedimento de pesagem das amostras coletadas.

Figura 4 - Simulação com Figura 5 - Pesagem das Figura 6 - Simulação com material da jazida 1. amostras coletadas.
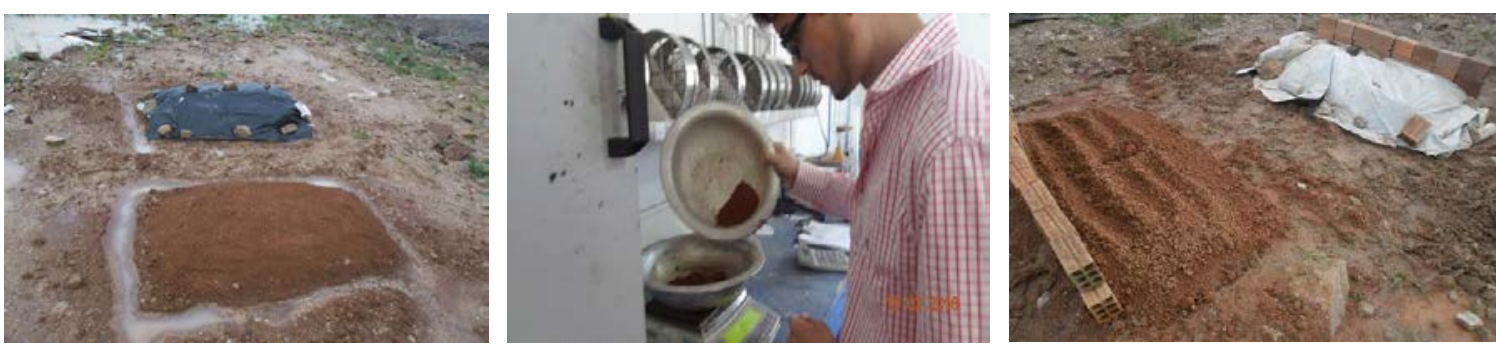

Fonte: Elaborado pelo autor, 2016. Fonte: Elaborado pelo autor, 2016. Fonte: Elaborado pelo autor, 2016.

\subsubsection{Resultados da simulação dos 4 aterros}

Entre os dias 15 e 24 de março de 2016, foi realizada a análise discriminada da variação horária no teor de umidade dos segmentos simulados. Essa fase do estudo foi feita para simular uma situação normal na frente de serviço, em que há a necessidade de aeração do material para alcançar a umidade ótima de compactação. O procedimento seguiu as seguintes etapas: (I) umedecimento do material no turno da manhã; (II) verificação do teor de umidade; (III) aeração durante o dia; e (IV) verificação no teor de umidade novamente. A partir desses dados, foi possível concluir que o decréscimo no teor de umidade do material oriundo da jazida 1 foi de $0,39 \% /$ hora e o da jazida 2 de $0,46 \%$ /hora, conforme resumo constante na tab.(1). 
Tabela 1 - Variação horária no teor de umidade dos solos provenientes das jazidas 1 e 2

\begin{tabular}{|c|c|c|c|c|c|}
\hline \multirow{2}{*}{\multicolumn{2}{|c|}{ DATA }} & \multicolumn{2}{|c|}{ JAZIDA 1} & \multicolumn{2}{|c|}{ JAZIDA 2} \\
\hline & & \multirow{2}{*}{$\begin{array}{c}\text { SIMULAÇÃO No } 1 \\
-0,29 \% / \text { hora }\end{array}$} & \multirow{2}{*}{$\begin{array}{c}\text { SIMULAÇÃO No } 2 \\
-0,37 \% / \text { hora }\end{array}$} & \multirow{2}{*}{$\begin{array}{c}\text { SIMULAÇÃO No } 3 \\
-0,61 \% / \text { hora }\end{array}$} & \multirow{2}{*}{$\begin{array}{c}\text { SIMULAÇÃO No } \mathbf{4} \\
-0,58 \% / \text { hora }\end{array}$} \\
\hline $15 / 03 / 2016$ & Terça-feira & & & & \\
\hline $16 / 03 / 2016$ & Quarta-feira & $-0,29 \% /$ hora & $-0,35 \% /$ hora & $-0,68 \% /$ hora & $-0,65 \% /$ hora \\
\hline $17 / 03 / 2016$ & Quinta-feira & $-0,36 \% /$ hora & $-0,38 \% /$ hora & $-0,37 \% /$ hora & $-0,37 \% /$ hora \\
\hline $18 / 03 / 2016$ & Sexta-feira & $-0,38 \% /$ hora & $-0,38 \% /$ hora & $-0,43 \% /$ hora & $-0,40 \% /$ hora \\
\hline $22 / 03 / 2016$ & Terça-feira & $-0,57 \% /$ hora & $-0,29 \% /$ hora & $-0,57 \% /$ hora & $-0,08 \% /$ hora \\
\hline $23 / 03 / 2016$ & Quarta-feira & $-0,41 \% /$ hora & $-0,34 \% /$ hora & $-0,37 \% /$ hora & $-0,48 \% /$ hora \\
\hline $24 / 03 / 2016$ & Quinta-feira & $-0,51 \% /$ hora & $-0,48 \% /$ hora & $-0,44 \% /$ hora & $-0,40 \% /$ hora \\
\hline \multicolumn{2}{|c|}{ MÉDIA } & \multicolumn{2}{|c|}{$-0,39 \% /$ hora } & \multicolumn{2}{|c|}{$-0,46 \% /$ hora } \\
\hline
\end{tabular}

Fonte: Elaborado pelo autor, 2016.

Além da variação demonstrada durante o período estudado, ocorreram dois dias de chuva, possibilitando o estudo comparativo entre os aterros simulados com e sem lona plástica em relação ao seu ganho de umidade após a chuva. Conforme figura 3 , os aterros foram divididos, para fins de coleta de material a ser ensaiado, em três pontos: A, B e C. A partir da média aritmética do teor de umidade entre os três pontos, foi feito o cálculo para concluir o quanto aumentou a umidade dos aterros com e sem lona. Esse procedimento foi realizado tanto para os materiais provenientes da jazida 1, como para os materiais da jazida 2 . A localização de cada ponto pode ser encontrada na fig. 3 com a união do número e letra das tabelas 2, 3, 4 e 5, coluna "Local". As tabelas supracitadas apresentam os resultados dos acréscimos nos teores de umidade dos aterros após a chuva com e sem lona plástica.

Tabela 2 - Resultado dos teores de umidade antes e depois da chuva ocorrida nos dias 19 e 20 de março de 2016 - segmento de aterro simulado com material oriundo da jazida 1.

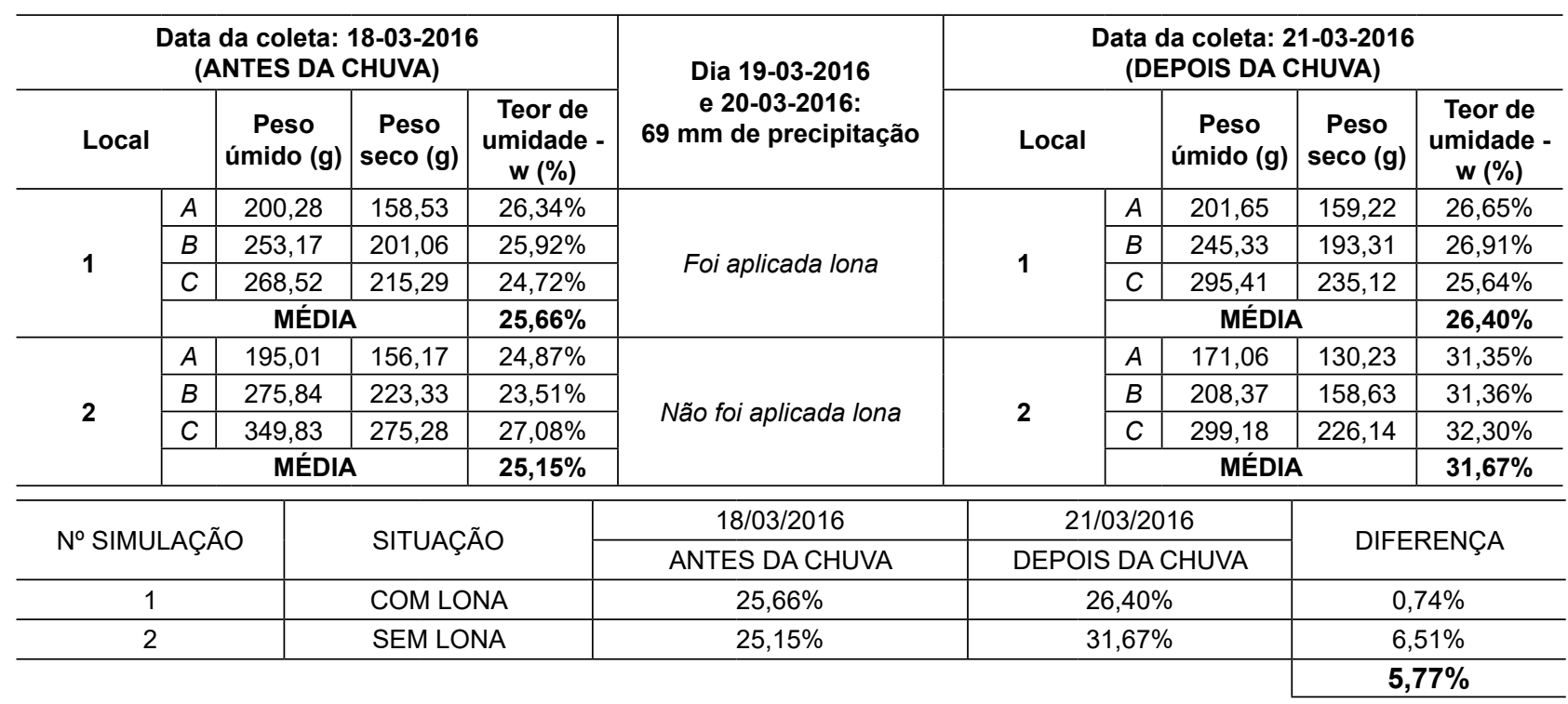

Fonte: Elaborado pelo autor, 2016.

Verifica-se que, após a precipitação, o segmento com aplicação de lona teve ganho de umidade 5,77 \% menor que o segmento sem lona. Considerando, então, que ao aerar o material da jazida 1, ele decresce em média 0,39\% por hora, pode-se concluir que o tempo necessário para abater essa diferença através de tratamento da camada para secagem do solo é de 14,79 horas de trabalho $(5,77 \% / 0,39 \%)$. 
Tabela 3 - Resultado dos teores de umidade antes e depois da chuva ocorrida nos dias 19 e 20 de março de 2016 - segmento de aterro simulado com material oriundo da jazida 2.

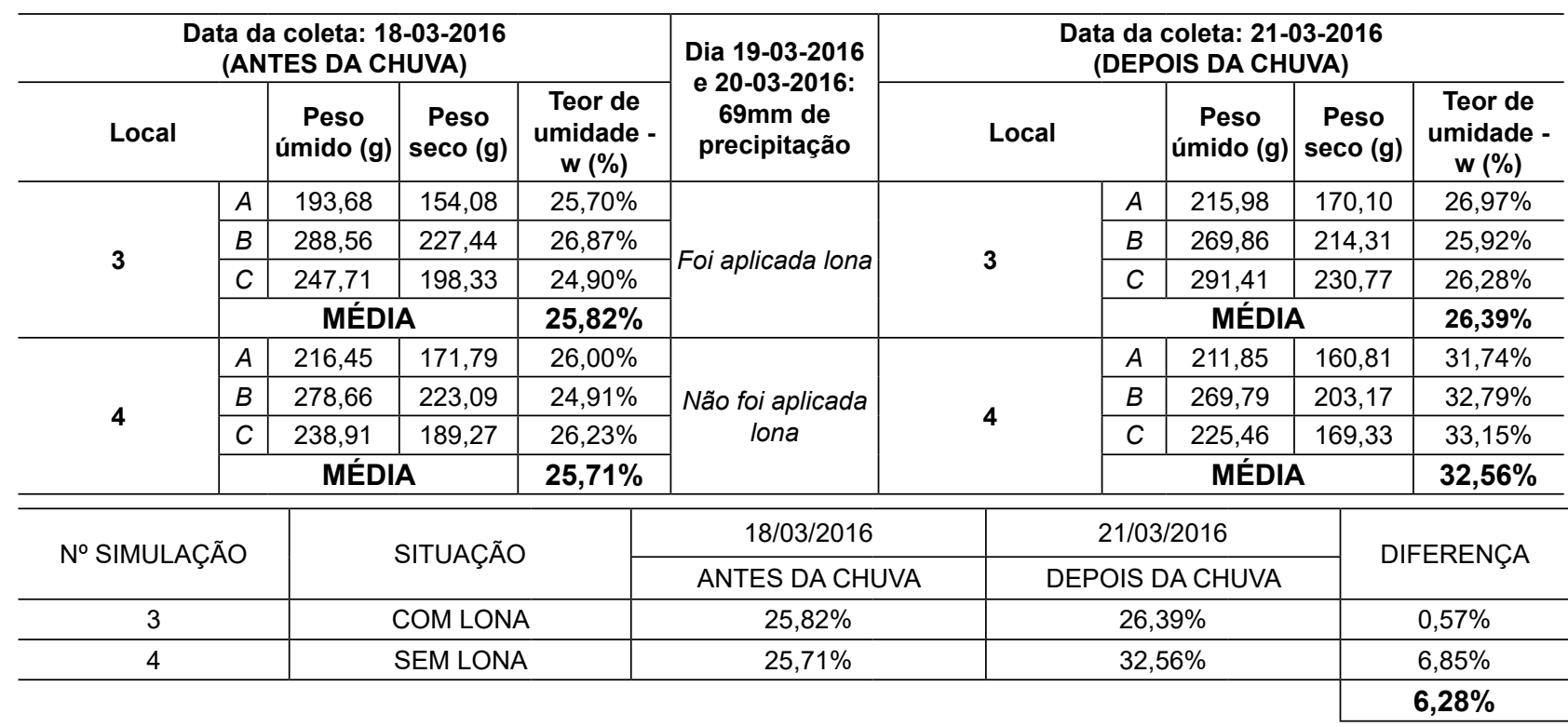

Fonte: Elaborado pelo autor, 2016.

O segmento em que não houve aplicação da lona ganhou 6,28 \% mais umidade que o segmento com Iona. O material oriundo da jazida 2 decresce, em média, 0,46 \% por hora ao ser aerado. Portanto, a aplicação da lona plástica gera, nesse caso, uma economia de 13,66 horas de trabalho tratando camada de aterro para alcançar a umidade ótima de compactação.

Tabela 4 - Resultado dos teores de umidade antes e depois da chuva ocorrida entre os dias 25 e 27 de março - segmento de aterro simulado com material oriundo da jazida 1.

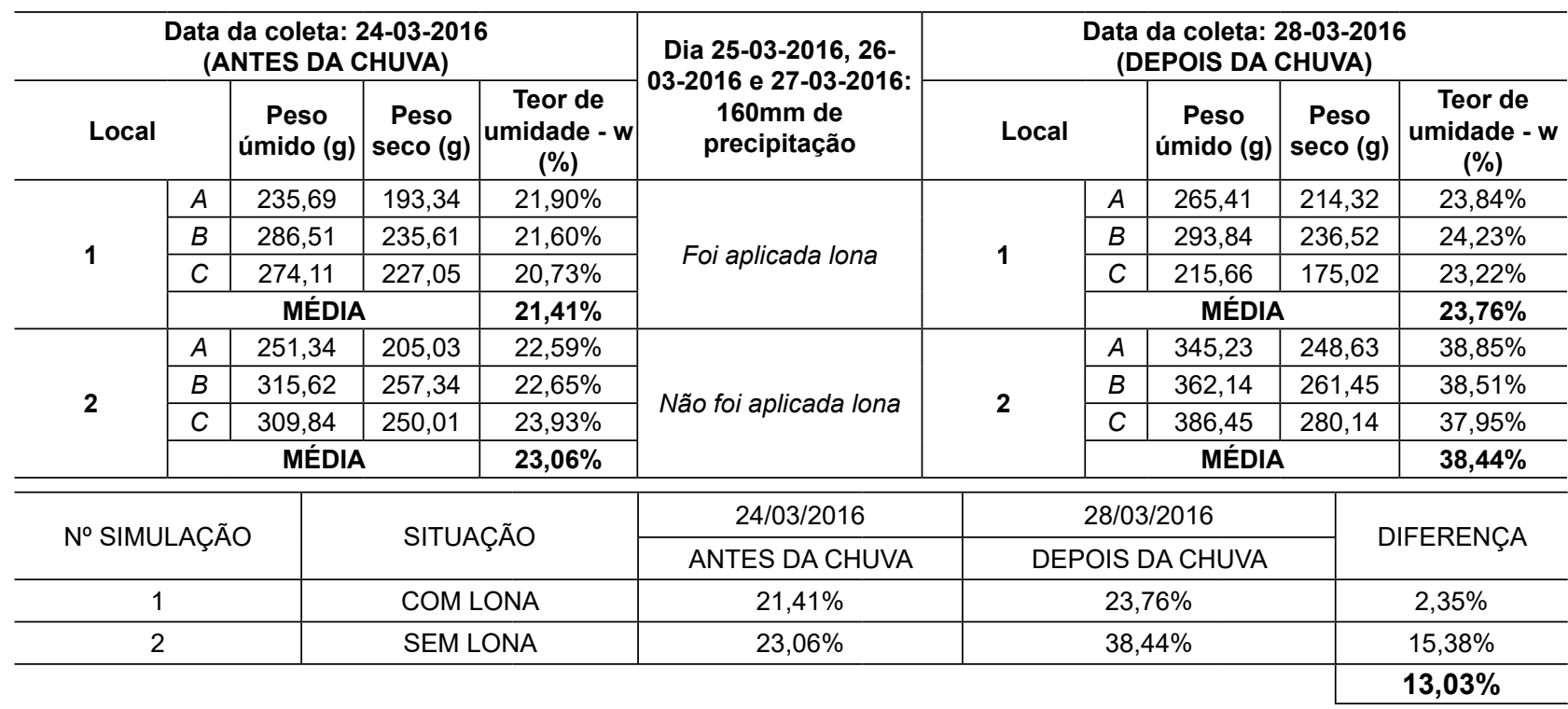

Fonte: Elaborado pelo autor, 2016.

Após a chuva, o segmento em que não houve aplicação da lona ganhou 13,03\% mais umidade que o segmento protegido com lona, ou seja, a aplicação da lona gera uma economia de 33,42 horas de trabalho. 
Tabela 5 - Resultado dos teores de umidade antes e depois da chuva ocorrida dias 25, 26 e 27 de março segmento de aterro simulado com material oriundo da jazida 2 .

\begin{tabular}{|c|c|c|c|c|c|c|c|c|c|c|}
\hline \multicolumn{5}{|c|}{$\begin{array}{l}\text { Data da coleta: 24-03-2016 } \\
\text { (ANTES DA CHUVA) }\end{array}$} & \multirow{2}{*}{$\begin{array}{c}\text { Dia 25-03-2016, 26- } \\
\text { 03-2016 e 27-03-2016: } \\
\text { 160mm de precipitação }\end{array}$} & \multicolumn{5}{|c|}{$\begin{array}{c}\text { Data da coleta: } 28-03-2016 \\
\text { (DEPOIS DA CHUVA) }\end{array}$} \\
\hline \multicolumn{2}{|c|}{ Local } & \multirow{2}{*}{\begin{tabular}{|c|}
$\begin{array}{c}\text { Peso } \\
\text { úmido }(\mathbf{g})\end{array}$ \\
265,34 \\
\end{tabular}} & \multirow{2}{*}{\begin{tabular}{|c|}
$\begin{array}{c}\text { Peso } \\
\text { seco }(\mathbf{g})\end{array}$ \\
215,32 \\
\end{tabular}} & $\begin{array}{c}\text { Teor de } \\
\text { umidade - } \\
\text { w (\%) } \\
\end{array}$ & & \multicolumn{2}{|c|}{ Local } & \multirow{2}{*}{\begin{tabular}{|c|}
$\begin{array}{c}\text { Peso } \\
\text { úmido }(\mathbf{g})\end{array}$ \\
309,55 \\
\end{tabular}} & \multirow{2}{*}{\begin{tabular}{|c|} 
Peso \\
seco (g)
\end{tabular}} & \multirow{2}{*}{\begin{tabular}{|c|}
$\begin{array}{c}\text { Teor de } \\
\text { umidade - } \\
\text { w (\%) }\end{array}$ \\
$25,64 \%$ \\
\end{tabular}} \\
\hline \multirow{4}{*}{3} & $A$ & & & $23,23 \%$ & \multirow{4}{*}{ Foi aplicada lona } & \multirow{4}{*}{3} & $A$ & & & \\
\hline & $B$ & 278,91 & 226,58 & $23,10 \%$ & & & $B$ & 311,24 & 249,78 & $24,61 \%$ \\
\hline & $C$ & 315,24 & 255,09 & $23,58 \%$ & & & $C$ & 314,60 & 252,12 & $24,78 \%$ \\
\hline & \multicolumn{3}{|c|}{ MÉDIA } & $23,30 \%$ & & & \multicolumn{3}{|c|}{ MÉDIA } & $25,01 \%$ \\
\hline \multirow{4}{*}{4} & $A$ & 365,21 & 299,35 & $22,00 \%$ & \multirow{4}{*}{ Não foi aplicada lona } & \multirow{4}{*}{4} & $A$ & 245,15 & 177,32 & $38,25 \%$ \\
\hline & $B$ & 366,92 & 298,74 & $22,82 \%$ & & & $B$ & 266,37 & 191,35 & $39,21 \%$ \\
\hline & $C$ & 309,75 & 254,63 & $21,65 \%$ & & & $C$ & 219,84 & 159,44 & $37,88 \%$ \\
\hline & \multicolumn{3}{|c|}{ MÉDIA } & $22,16 \%$ & & & \multicolumn{3}{|c|}{ MÉDIA } & $38,45 \%$ \\
\hline \multirow{2}{*}{\multicolumn{2}{|c|}{ Nº SIMULAÇÃO }} & & \multirow{2}{*}{\multicolumn{2}{|c|}{ SITUAÇÃO }} & $24 / 03 / 2016$ & & $3 / 2$ & & \multirow{2}{*}{\multicolumn{2}{|c|}{ DIFERENÇA }} \\
\hline & & & & & ANTES DA CHUVA & & $\mathrm{DA}$ & CHUVA & & \\
\hline & & & COM LON & & $23,30 \%$ & &, 01 & & & $71 \%$ \\
\hline & & & SEM LON & & $22,16 \%$ & & 3,45 & & & $29 \%$ \\
\hline & & & & & & & & & & $58 \%$ \\
\hline
\end{tabular}

Fonte: Elaborado pelo autor, 2016.

Após a chuva, o segmento em que não houve aplicação da lona ganhou $14,58 \%$ mais umidade que o segmento com lona, economia de 31,72 horas de trabalho.

\subsection{Estudo de caso no segmento experimental, localizado do $\mathrm{km} \mathrm{481,460} \mathrm{ao} \mathrm{km} \mathrm{481,660}$}

Em setembro de 2014 foi realizado um aterro experimental no segmento compreendido entre o $\mathrm{km}$ 481,460 e o km 481,660. A previsão do tempo foi monitorada pelo WindGuru. Depois de constatado que havia previsão de chuva para a noite, foi realizada a aplicação da lona plástica entre os km 481,460 e 481,560 e mantido apenas o procedimento padrão de selagem de aterro nos outros $100 \mathrm{~m}$ restantes. As figuras de $7 \mathrm{a}$ 10 mostram o estudo de caso no segmento experimental.

Figura 7 - Foto aérea do local estudado. Figura 8 - Lona aplicada no local estudado

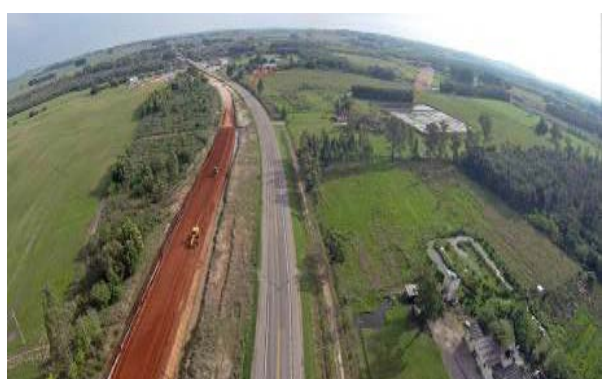

Fonte: Elaborado pelo autor, 2014.

Figura 9 - Pluviômetro

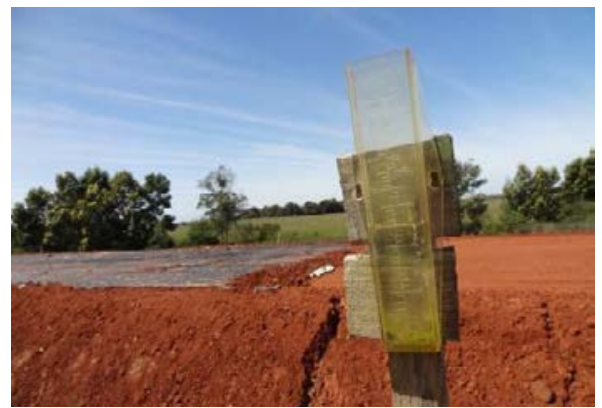

Fonte: Elaborado pelo autor, 2014.

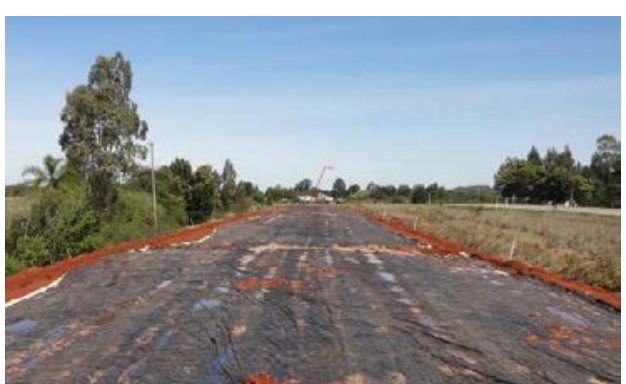

Fonte: Elaborado pelo autor, 2014.

Figura 10 - Colocação de lona plástica.

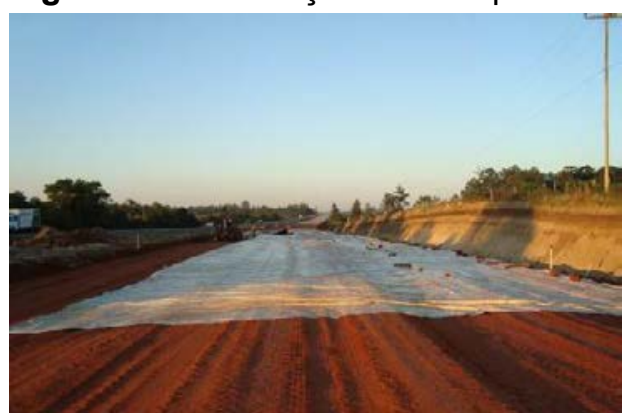

Fonte: Elaborado pelo autor, 2014. 


\subsubsection{Resultados do estudo de caso no segmento experimental localizado do km 481,460 ao 481,660}

A tabela 6 apresenta o resultado dos teores de umidade antes e depois da chuva no segmento experimental compreendido entre o $\mathrm{km} \mathrm{481,460} \mathrm{e} \mathrm{o} \mathrm{km} \mathrm{481,660.}$

Tabela 6 - Resultado dos teores de umidade antes e depois da chuva - segmento experimental compreendido entre o km 481,460 e o km 481,660.

\begin{tabular}{|c|c|c|c|c|c|c|c|c|c|c|}
\hline \multicolumn{5}{|c|}{$\begin{array}{l}\text { Data da coleta: } 10-09-2014 \\
\text { (ANTES DA CHUVA) }\end{array}$} & \multirow{2}{*}{$\begin{array}{l}50 \mathrm{~mm} \text { de } \\
\text { precipitação }\end{array}$} & \multicolumn{5}{|c|}{$\begin{array}{l}\text { Data da coleta: } 11-09-2014 \\
\text { (DEPOIS DA CHUVA) }\end{array}$} \\
\hline \multicolumn{2}{|c|}{ Local } & \multirow{2}{*}{\begin{tabular}{|c|}
$\begin{array}{c}\text { Peso } \\
\text { úmido }(\mathbf{g})\end{array}$ \\
300,40 \\
\end{tabular}} & \multirow{2}{*}{\begin{tabular}{|c|}
$\begin{array}{c}\text { Peso } \\
\text { seco }(\mathbf{g})\end{array}$ \\
239,40 \\
\end{tabular}} & \multirow{2}{*}{\begin{tabular}{|c|}
$\begin{array}{c}\text { Teor de } \\
\text { umidade - w } \\
\text { (\%) }\end{array}$ \\
$25,48 \%$ \\
\end{tabular}} & & \multicolumn{2}{|c|}{ Local } & \multirow{2}{*}{\begin{tabular}{|c|}
$\begin{array}{c}\text { Peso } \\
\text { úmido }(\mathbf{g})\end{array}$ \\
319,10 \\
\end{tabular}} & \multirow{2}{*}{\begin{tabular}{|c|}
$\begin{array}{c}\text { Peso } \\
\text { seco }(\mathbf{g})\end{array}$ \\
249,40
\end{tabular}} & \multirow{2}{*}{\begin{tabular}{|c|}
$\begin{array}{c}\text { Teor de } \\
\text { umidade - w } \\
\text { (\%) }\end{array}$ \\
$27,95 \%$ \\
\end{tabular}} \\
\hline \multirow{4}{*}{481,460} & LD & & & & \multirow{4}{*}{ Foi aplicada lona } & \multirow{4}{*}{481,460} & LD & & & \\
\hline & EIXO & 375,80 & 303,60 & $23,78 \%$ & & & EIXO & 335,80 & 265,10 & $26,67 \%$ \\
\hline & LE & 378,90 & 304,10 & $24,60 \%$ & & & LE & 319,60 & 252,30 & $26,67 \%$ \\
\hline & \multicolumn{3}{|c|}{ MÉDIA } & $24,62 \%$ & & & \multicolumn{3}{|c|}{ MÉDIA } & $27,10 \%$ \\
\hline \multirow{4}{*}{481,560} & LD & 301,30 & 241,30 & $24,87 \%$ & \multirow{4}{*}{ Foi aplicada Iona } & \multirow{4}{*}{481,560} & LD & 331,10 & 259,40 & $27,64 \%$ \\
\hline & EIXO & 380,70 & 304,30 & $25,11 \%$ & & & EIXO & 311,00 & 244,50 & $27,20 \%$ \\
\hline & LE & 397,10 & 316,90 & $25,31 \%$ & & & LE & 302,20 & 233,90 & $29,20 \%$ \\
\hline & \multicolumn{3}{|c|}{ MÉDIA } & $25,09 \%$ & & & \multicolumn{3}{|c|}{ MÉDIA } & $28,01 \%$ \\
\hline \multirow{4}{*}{481,660} & LD & 390,20 & 308,10 & $26,65 \%$ & \multirow{4}{*}{ Não foi aplicada lona } & \multirow{4}{*}{481,660} & LD & 309,70 & 234,10 & $32,29 \%$ \\
\hline & EIXO & 334,30 & 264,30 & $26,49 \%$ & & & EIXO & 319,00 & 239,50 & $33,19 \%$ \\
\hline & LE & 315,20 & 248,20 & $26,99 \%$ & & & \begin{tabular}{|l|}
$\mathrm{LE}$ \\
\end{tabular} & 331,00 & 251,90 & $31,40 \%$ \\
\hline & \multicolumn{3}{|c|}{ MÉDIA } & $26,71 \%$ & & & \multicolumn{3}{|c|}{ MÉDIA } & $32,30 \%$ \\
\hline \multirow{2}{*}{\multicolumn{4}{|c|}{ SITUAÇÃO }} & \multirow{2}{*}{\multicolumn{2}{|c|}{$\begin{array}{c}\text { 10/09/2014 } \\
\text { ANTES DA CHUVA }\end{array}$}} & \multirow{2}{*}{\multicolumn{3}{|c|}{$\begin{array}{c}11 / 09 / 2014 \\
\text { DEPOIS DA CHUVA }\end{array}$}} & \multirow{2}{*}{\multicolumn{2}{|c|}{ DIFERENÇA }} \\
\hline & & & & & & & & & & \\
\hline \multicolumn{4}{|c|}{ COM LONA } & \multicolumn{2}{|c|}{$24,86 \%$} & \multicolumn{3}{|c|}{$27,56 \%$} & \multicolumn{2}{|r|}{$2,70 \%$} \\
\hline & SEI & U LONA & & & $26,71 \%$ & & $32,30 \%$ & & & $5,59 \%$ \\
\hline & & & & & & & & & & $2,89 \%$ \\
\hline
\end{tabular}

Fonte: Elaborado pelo autor, 2014.

Percebe-se que os 100 metros sem aplicação da lona plástica tiveram um ganho de umidade 2,89 \% maior que o segmento coberto pela lona, gerando uma economia de 7,41 horas de trabalho.

\subsection{Estudo de caso no segmento junto ao aterro de acesso do viaduto Turuçu, realizado com muro de terra armada (MTA)}

O MTA está localizado entre o km 483,075 e o km 483,166. O estudo ocorreu no lado sul do viaduto, no corpo do aterro, onde foi realizada, anteriormente à chuva, a aplicação de lona plástica em um lado da obra (Muro M4, conforme nomenclatura do projeto) e no outro não (Muro M6, conforme nomenclatura do projeto). Assim como no outro segmento estudado, o acompanhamento da previsão do tempo foi feito através do site WindGuru e foram estudados dois dias de chuva. A figura 11 apresenta a planta do muro sul e as figuras 12 a 15 demonstram o procedimento junto ao muro.

Figura 11 - Planta do muro sul.

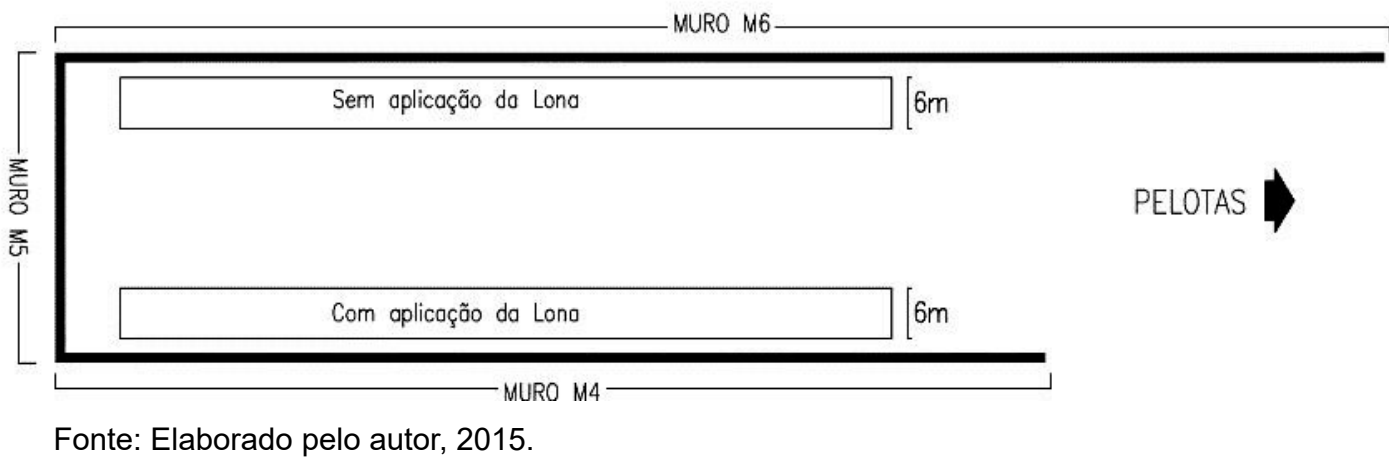


Figura 12 - Colocação da lona plástica.

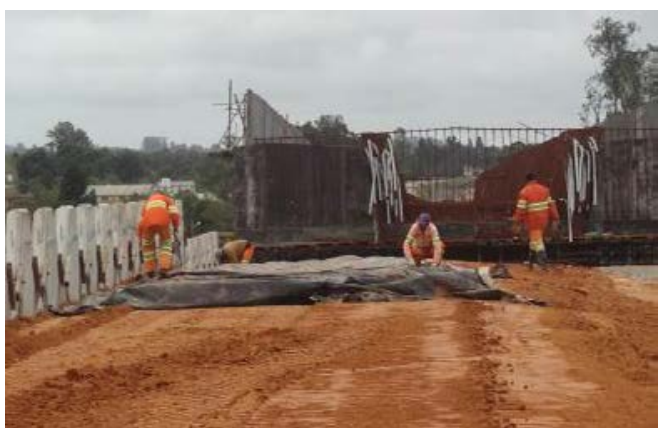

Fonte: Elaborado pelo autor, 2015.

Figura 14 - Coleta de amostra antes da ocorrência de chuva

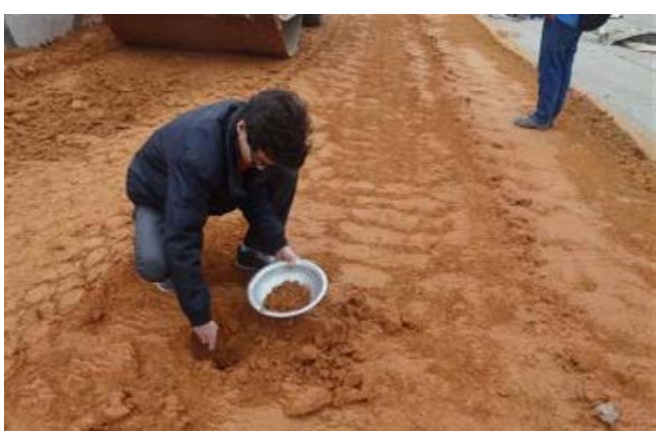

Fonte: Elaborado pelo autor, 2015.
Figura 13 - Ocorrência de chuva.

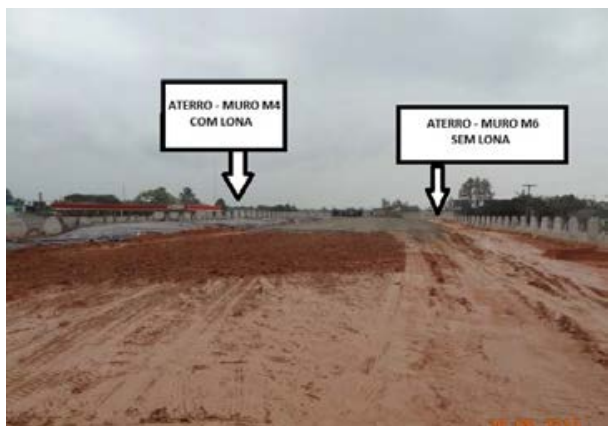

Fonte: Elaborado pelo autor, 2015.

Figura 15 - Compactação - MTA.

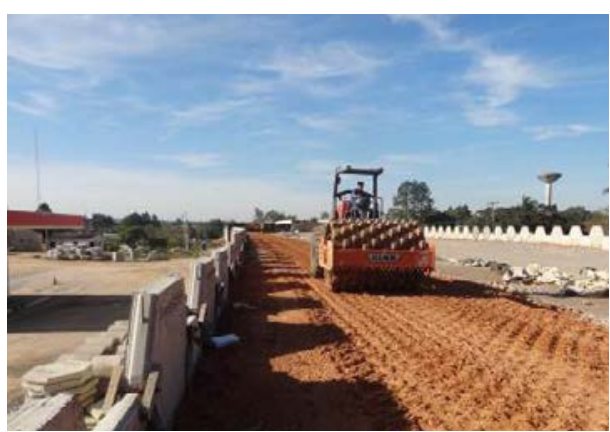

Fonte: Elaborado pelo autor, 2015.

3.4.1 Resultados do segmento junto ao aterro de acesso do viaduto Turuçu, realizado com muro de terra armada (MTA).

As tabelas 7 e 8 apresentam os resultados dos teores de umidade do solo antes e depois dos dias em que ocorreram precipitações.

Tabela 7 - Resultado dos teores de umidade antes e depois da chuva ocorrida em 26 de agosto de 2015 -segmento experimental junto ao muro de terra armada (2 lados).

\begin{tabular}{|c|c|c|c|c|c|c|c|c|}
\hline \multicolumn{4}{|c|}{$\begin{array}{l}\text { Data da coleta: } 25-08-2015 \\
\text { (ANTES DA CHUVA) }\end{array}$} & \multirow{2}{*}{$\begin{array}{c}\text { Dia 26-08-2015: } \\
\text { 15mm de } \\
\text { precipitação }\end{array}$} & \multicolumn{4}{|c|}{$\begin{array}{l}\text { Data da coleta: } 27-08-2015 \\
\text { (DEPOIS DA CHUVA) }\end{array}$} \\
\hline Local & $\begin{array}{c}\text { Peso } \\
\text { úmido }(\mathrm{g})\end{array}$ & $\begin{array}{c}\text { Peso } \\
\operatorname{seco}(g)\end{array}$ & $\begin{array}{c}\text { Teor de } \\
\text { umidade - w } \\
(\%)\end{array}$ & & Local & $\begin{array}{c}\text { Peso } \\
\text { úmido }(g)\end{array}$ & $\begin{array}{c}\text { Peso } \\
\text { seco }(g)\end{array}$ & $\begin{array}{c}\text { Teor de } \\
\text { umidade - w } \\
(\%)\end{array}$ \\
\hline \multirow{4}{*}{ M4 } & 203,30 & 161,60 & $25,80 \%$ & \multirow{4}{*}{ Foi aplicada lona } & \multirow{4}{*}{ M4 } & 240,00 & 189,10 & $26,92 \%$ \\
\hline & 209,30 & 171,10 & $22,33 \%$ & & & 238,57 & 192,31 & $24,05 \%$ \\
\hline & 218,70 & 178,20 & $22,73 \%$ & & & 231,32 & 186,22 & $24,22 \%$ \\
\hline & \multicolumn{2}{|c|}{ MÉDIA } & $23,62 \%$ & & & \multicolumn{2}{|c|}{ MÉDIA } & $25,06 \%$ \\
\hline \multirow{4}{*}{ M6 } & 218,40 & 176,33 & $23,86 \%$ & \multirow{4}{*}{ Não foi aplicada lona } & \multirow{4}{*}{ M6 } & 213,93 & 162,17 & $31,92 \%$ \\
\hline & 215,19 & 173,50 & $24,03 \%$ & & & 214,42 & 165,32 & $29,70 \%$ \\
\hline & 208,87 & 168,20 & $24,18 \%$ & & & 221,68 & 170,60 & $29,94 \%$ \\
\hline & \multicolumn{2}{|c|}{ MÉDIA } & $24,02 \%$ & & & \multicolumn{2}{|c|}{ MÉDIA } & $30,52 \%$ \\
\hline & \multirow{2}{*}{\multicolumn{2}{|c|}{ SITUAÇÃO }} & \multicolumn{2}{|c|}{$25 / 08 / 2015$} & \multicolumn{2}{|c|}{$27 / 08 / 2015$} & \multirow{2}{*}{\multicolumn{2}{|c|}{ DIFERENÇA }} \\
\hline & & & \multicolumn{2}{|c|}{ ANTES DA CHUVA } & \multicolumn{2}{|c|}{ DEPOIS DA CHUVA } & & \\
\hline \multicolumn{3}{|c|}{ COM LONA } & \multicolumn{2}{|c|}{$23,62 \%$} & \multicolumn{2}{|c|}{$25,06 \%$} & \multicolumn{2}{|c|}{$1,44 \%$} \\
\hline \multicolumn{3}{|c|}{ SEM LONA } & & $24,02 \%$ & \multicolumn{2}{|c|}{$30,52 \%$} & \multicolumn{2}{|c|}{$6,50 \%$} \\
\hline & & & & & & & \multicolumn{2}{|c|}{$5,05 \%$} \\
\hline
\end{tabular}

Fonte: Elaborado pelo autor, 2015. 
Depois da chuva, o lado sem aplicação da lona ganhou 5,05 \% a mais de umidade que o lado com aplicação, resultando em uma economia de 10,99 horas de trabalho no caso em que foi aplicada a proteção com lona.

Tabela 8 - Resultado dos teores de umidade antes e depois da chuva - segmento experimental junto ao muro de terra armada (2 lados).

\begin{tabular}{|c|c|c|c|c|c|c|c|c|}
\hline \multicolumn{4}{|c|}{$\begin{array}{l}\text { Data da coleta: 03-09-2015 } \\
\text { (ANTES DA CHUVA) }\end{array}$} & \multirow{2}{*}{$\begin{array}{c}\text { Dia 03-09-2015: } \\
\text { 19mm de } \\
\text { precipitação }\end{array}$} & \multicolumn{4}{|c|}{$\begin{array}{l}\text { Data da coleta: } 04-09-2015 \\
\text { (DEPOIS DA CHUVA) }\end{array}$} \\
\hline Local & $\begin{array}{c}\text { Peso } \\
\text { úmido }(g)\end{array}$ & $\begin{array}{c}\text { Peso } \\
\operatorname{seco}(g)\end{array}$ & \begin{tabular}{|c|} 
Teor de \\
umidade - w \\
$(\%)$
\end{tabular} & & Local & $\begin{array}{l}\text { Peso } \\
\text { úmido }(g)\end{array}$ & $\begin{array}{c}\text { Peso } \\
\operatorname{seco}(g)\end{array}$ & $\begin{array}{c}\text { Teor de } \\
\text { umidade - w } \\
(\%) \\
\end{array}$ \\
\hline \multirow{4}{*}{ M4 } & 242,10 & 204,20 & $18,56 \%$ & \multirow{4}{*}{ Foi aplicada Iona } & \multirow{4}{*}{ M4 } & 287,60 & 231,12 & $24,44 \%$ \\
\hline & 219,30 & 186,80 & $17,40 \%$ & & & 290,41 & 234,10 & $24,05 \%$ \\
\hline & 210,31 & 177,12 & $18,74 \%$ & & & 267,77 & 215,98 & $23,98 \%$ \\
\hline & \multicolumn{2}{|c|}{ MÉDIA } & $18,23 \%$ & & & \multicolumn{2}{|c|}{ MÉDIA } & $24,16 \%$ \\
\hline \multirow{4}{*}{ M6 } & 237,50 & 200,60 & $18,39 \%$ & \multirow{4}{*}{ Não foi aplicada lona } & \multirow{4}{*}{ M6 } & 245,90 & 189,00 & $30,11 \%$ \\
\hline & 231,32 & 197,30 & $17,24 \%$ & & & 266,10 & 205,42 & $29,54 \%$ \\
\hline & 227,90 & 192,48 & $18,40 \%$ & & & 231,32 & 177,36 & $30,42 \%$ \\
\hline & \multicolumn{2}{|c|}{ MÉDIA } & $18,01 \%$ & & & \multicolumn{2}{|c|}{ MÉDIA } & $30,02 \%$ \\
\hline \multirow{2}{*}{\multicolumn{3}{|c|}{ SITUAÇÃO }} & \multicolumn{2}{|c|}{ 03/09/2015 } & \multicolumn{2}{|c|}{ 04/09/2015 } & \multirow{2}{*}{\multicolumn{2}{|c|}{ DIFERENÇA }} \\
\hline & & & ANTES D/ & A CHUVA & DEPOIS D, & UVA & & \\
\hline \multicolumn{3}{|c|}{ COM LONA } & \multicolumn{2}{|c|}{$18,23 \%$} & \multicolumn{2}{|c|}{$24,16 \%$} & \multicolumn{2}{|c|}{$5,92 \%$} \\
\hline \multicolumn{3}{|c|}{ SEM LONA } & \multicolumn{2}{|c|}{$18,01 \%$} & \multicolumn{2}{|c|}{$30,02 \%$} & \multicolumn{2}{|c|}{$12,01 \%$} \\
\hline & & & & & & & & $09 \%$ \\
\hline
\end{tabular}

Fonte: Elaborado pelo autor, 2015.

Após a chuva, o lado sem aplicação da lona ganhou 6,09 \% a mais de umidade que o lado em que a Iona foi utilizada. Constatou-se, então, uma economia de 13,25 horas de trabalho no caso em que foi aplicada a proteção com lona.

Em todas as sete situações estudadas, o aterro coberto por lona teve ganho de umidade menor que o aterro protegido pelo procedimento convencional.

\subsection{Análise financeira}

Foi utilizado o Sistema de Custos Referenciais de Obras (SICRO), do Departamento Nacional de Infraestrutura de Transportes, com análise direta no serviço de compactação de aterro a $100 \%$ proctor normal, código SICRO 5502978, Rio Grande do Sul, data base outubro/2018. Os dados necessários para avaliação financeira são: i) diferença no teor de umidade após a chuva entre o aterro com lona plástica e o sem lona plástica (estudado nos tópicos anteriores); ii) média da variação horária no teor de umidade do solo durante a execução da aeração do solo; iii) custo de aquisição da lona plástica (pesquisa feita nas empresas da região em outubro de 2018), bem como da mão de obra necessária para sua aplicação; iv) custo horário do serviço de compactação a $100 \%$ PN.

Os dois primeiros itens citados anteriormente foram estudados no decorrer deste trabalho. A seguir, serão tratados o terceiro e quarto e, posteriormente, feita a análise dos custos do estudo.

(I) Custo de aquisição da lona plástica: Para obter esse dado, em outubro de 2018 foi realizada pesquisa em empresas da região, na qual se constatou um custo médio do metro quadrado de $R \$ 1,37$. Trabalha-se com segmentos de aproximadamente $200 \mathrm{~m}$ de extensão e largura média de $11,50 \mathrm{~m}$. Portanto, foi considerada a compra de $200 \mathrm{~m} \times 11,50 \mathrm{~m}=2.300 \mathrm{~m}^{2}$. Tem-se, então, $\mathrm{R} \$ 3.151,00$. É importante observar que esse custo da Iona é de aquisição, podendo ser utilizada com qualidade por aproximadamente sete meses (tempo constatado em aplicações nos trechos do lote 8). 
(II) Custo de mão de obra: para aplicação e retirada da lona plástica, são necessários três serventes de obra por aproximadamente 30 minutos (15 min. para aplicação e $15 \mathrm{~min}$. para retirada), dado também verificado durante a execução dos serviços no trecho da BR 116/RS, lote 8. De acordo com SICRO (DNIT, 2018), o custo horário do servente, com encargos sociais, é de $R \$ 17,5188$. Por conseguinte, considerando 3 serventes por 0,50 horas, tem-se um custo de $R \$ 26,28$. Percebe-se que é um valor pequeno. Mesmo assim, será considerado na análise.

(III) Custo horário total de execução do serviço de compactação a 100\% PN = R \$ 472,8158 (Código SICRO 5502978).

É importante considerar que a análise dos custos foi realizada baseando-se no custo da diferença entre as duas situações: com lona e sem lona plástica. Conforme estudo da variação horária no teor de umidade das duas jazidas estudadas, percebeu-se que o material oriundo da jazida 1 teve decréscimo de 0,39 \% por hora e o da jazida 2, 0,46\%.

Por meio de pesquisa na região de Pelotas-RS, constatou-se o custo de aquisição da lona plástica e, de acordo com o SICRO (DNIT, 2018), o custo de mão de obra, conforme tab.9.

Tabela 9 - Custo de aquisição + aplicação da lona plástica.

\begin{tabular}{|c|c|c|c|c|c|c|c|c|c|}
\hline \multicolumn{3}{|c|}{$\begin{array}{l}\text { Dimensões de trabalho do aterro consi- } \\
\text { deradas para fins de cálculo }\end{array}$} & \multicolumn{2}{|c|}{ Custo da lona } & \multicolumn{4}{|c|}{ Custo de mão de obra } & \multirow[b]{2}{*}{$\begin{array}{l}\text { Custo } \\
\text { total }\end{array}$} \\
\hline $\begin{array}{l}\text { Comprimento } \\
(\mathrm{m})\end{array}$ & Largura $(\mathrm{m})$ & Área $\left(m^{2}\right)$ & $\begin{array}{l}\text { Custo } \\
\text { unitário }\end{array}$ & Custo total & $\begin{array}{c}\text { Quantiade de } \\
\text { Serventes }\end{array}$ & $\begin{array}{l}\text { Horas / } \\
\text { servente }\end{array}$ & $\begin{array}{l}\text { Custo horário } \\
\text { do servente } \\
\text { com encargos }\end{array}$ & $\begin{array}{c}\text { Custo de } \\
\text { mão de obra }\end{array}$ & \\
\hline 200,00 & 11,50 & $2.300,00$ & $\mathrm{R} \$ 1,37$ & $\mathrm{R} \$ 3.151,00$ & 3 & 0,50 & 17,52 & $\mathrm{R} \$ 26,28$ & $\begin{array}{c}\mathrm{R} \$ \\
3.177,28\end{array}$ \\
\hline
\end{tabular}

Fonte: Elaborado pelo autor, 2009.

Os dados finais do estudo financeiro, por segmento, são apresentados na tab.10.

Tabela 10 - Resultados finais por segmento estudado.

\begin{tabular}{|c|c|c|c|c|c|c|c|c|c|}
\hline Descrição & $\begin{array}{l}\text { Precipitação } \\
(\mathrm{mm})\end{array}$ & Jazida & $\begin{array}{l}\text { Variação } \\
\text { horária } \\
\text { no teor de } \\
\text { umidade } \\
\text { (a) }\end{array}$ & $\begin{array}{l}\text { Diferença de } \\
\text { umidade do } \\
\text { aterro com } \\
\text { lona para } \\
\text { o sem lona } \\
\text { (b) }\end{array}$ & $\begin{array}{c}\text { Custo horá- } \\
\text { rio de execu- } \\
\text { ção (SICRO } \\
\text { Out/18 - RS) } \\
\text { (c) }\end{array}$ & $\begin{array}{c}\text { Tempo } \\
\text { necessário } \\
\text { para abater } \\
\text { a diferença } \\
\text { (hrs) (d) }=(\text { b) } / \\
\text { (a) }\end{array}$ & $\begin{array}{l}\text { Custo da } \\
\text { diferença (e) } \\
=(\text { c) } \cdot \text { (d) }\end{array}$ & $\begin{array}{c}\text { Custo de } \\
\text { aquisição + } \\
\text { aplicação da } \\
\text { lona (f) }\end{array}$ & $\begin{array}{l}\text { Resultado } \\
\text { financeiro } \\
(\mathrm{g})=(\mathrm{e}) \text { - (f) }\end{array}$ \\
\hline $\begin{array}{l}\text { Simulação: Chuva } 19 \text { e } \\
20 \text { de março/2016 }\end{array}$ & 69 & 1 & $-0,39 \%$ & $5,77 \%$ & $\mathrm{R} \$ 472,82$ & 14,96 & $\mathrm{R} \$ 7.073,06$ & $\mathrm{R} \$ 3.177,28$ & $R \$ 3.895,78$ \\
\hline $\begin{array}{l}\text { Simulação: Chuva } 19 \text { e } \\
20 \text { de março/2016 }\end{array}$ & 69 & 2 & $-0,46 \%$ & $6,28 \%$ & $\mathrm{R} \$ 472,82$ & 13,66 & $\mathrm{R} \$ 6.460,80$ & $\mathrm{R} \$ 3.177,28$ & $\mathrm{R} \$ 3.283,52$ \\
\hline $\begin{array}{l}\text { Simulação: Chuva } 25, \\
26 \text { e } 27 \text { de março/2016 }\end{array}$ & 160 & 1 & $-0,39 \%$ & $13,03 \%$ & $\mathrm{R} \$ 472,82$ & 33,78 & $\mathrm{R} \$ 15.972,61$ & $\mathrm{R} \$ 3.177,28$ & $\mathrm{R} \$ 12.795,33$ \\
\hline $\begin{array}{l}\text { Simulação: Chuva } 25, \\
26 \text { e } 27 \text { de março/2016 }\end{array}$ & 160 & 2 & $-0,46 \%$ & $14,58 \%$ & $\mathrm{R} \$ 472,82$ & 31,72 & $\mathrm{R} \$ 14.999,76$ & $\mathrm{R} \$ 3.177,28$ & $\mathrm{R} \$ 11.822,48$ \\
\hline $\begin{array}{l}\text { Situação real estudada } \\
\text { em } 2015\end{array}$ & 15 & 2 & $-0,46 \%$ & $5,05 \%$ & $\mathrm{R} \$ 472,82$ & 10,99 & $\mathrm{R} \$ 5.195,39$ & $\mathrm{R} \$ 3.177,28$ & $\mathrm{R} \$ 2.018,11$ \\
\hline $\begin{array}{l}\text { Situação real estudada } \\
\text { em } 2015\end{array}$ & 19 & 2 & $-0,46 \%$ & $6,09 \%$ & $\mathrm{R} \$ 472,82$ & 13,25 & $\mathrm{R} \$ 6.265,33$ & $\mathrm{R} \$ 3.177,28$ & $R \$ 3.088,05$ \\
\hline $\begin{array}{l}\text { Situação real estudada } \\
\text { em } 2014\end{array}$ & 50 & 1 & $-0,39 \%$ & $2,89 \%$ & $\mathrm{R} \$ 472,82$ & 7,49 & $\mathrm{R} \$ 3.542,66$ & $\mathrm{R} \$ 3.177,28$ & $\mathrm{R} \$ 365,38$ \\
\hline
\end{tabular}

Fonte: Elaborado pelo autor, 2009. 


\section{Conclusão}

Diante dos dados apresentados, pode-se observar que a utilização de lona plástica para proteção de aterros rodoviários contra precipitações é uma solução viável do ponto de vista técnico e de custos. Foi realizado o estudo de sete situações de chuva distintas no estado do Rio Grande do Sul, e em todos os casos a utilização da lona proporcionou economia e agilidade na execução dos serviços em questão, além do resultado financeiro obtido. Outra vantagem percebida é a economia de tempo, o que proporciona agilidade no avanço para o início de serviços posteriores à terraplenagem.

Cabe salientar, ainda, que o custo da lona é de aquisição e que o insumo pode ser utilizado com qualidade por aproximadamente sete meses. Sendo assim, os resultados apresentados representam uma análise inicial pois, a partir do momento em que for realizado o segundo aterro após a aquisição da lona, a diferença será maior porque haverá apenas o custo de aplicação da lona plástica, desde que ocorra dentro do seu período de validade. Além disso, ao considerar que a obra se encontra em alta produção de terraplenagem, várias frentes de serviço estariam em andamento e esse resultado poderia ser multiplicado pela quantidade de aterros executados simultaneamente.

A utilização da lona proporciona economia e agilidade nos serviços de terraplenagem. O estudo realizado, por conseguinte, permite concluir a eficácia na utilização de métodos não tradicionais em substituição ao convencional.

\section{Referências}

ASSOCIAÇÃO BRASILEIRA DE NORMAS TÉCNICAS. NBR 7184 - Solo - Análise granulométrica. Rio de Janeiro: ABNT, 1984.

DEPARTAMENTO NACIONAL DE INFRAESTRUTURA DE TRANSPORTES. Sistema de custos referenciais de obras. Rio Grande do Sul: DNIT, 2018.

INSTITUTO DE PESQUISAS RODOVIÁRIAS. DNER-ME 129 - Solos - compactação utilizando amostras não trabalhadas. Departamento Nacional de Estradas de Rodagem. Rio de Janeiro: IPR, 1994.

INSTITUTO DE PESQUISAS RODOVIÁRIAS. DNER-ME 122 - Solos - determinação do limite de liquidez método de referência e método expedito. Rio de Janeiro: IPR, 1994 a.

INSTITUTO DE PESQUISAS RODOVIÁRIAS. DNER-ME 82 - Solos - determinação do limite de plasticidade. Rio de Janeiro: IPR, 1994b.

INSTITUTO DE PESQUISAS RODOVIÁRIAS. DNER-ME 213 - Solos - determinação do teor de umidade. Rio de Janeiro: IPR, 1994c.

INSTITUTO DE PESQUISAS RODOVIÁRIAS. Manual de pavimentação. 3. ed. Rio de Janeiro: IPR, 2006. INSTITUTO DE PESQUISAS RODOVIÁRIAS. ES 108 - Terraplenagem - Aterros. Rio de Janeiro: IPR, 2009.

PINTO, C. de S. Curso básico de mecânica dos solos em 16 Aulas. 3. ed. São Paulo: Oficina dos Textos, 2006. 


\section{Sobre os autores}

\section{Ítalo Martins e Cunha}

Graduado em Engenharia Civil pela Universidade Católica de Pelotas (UCPEL). MBA em Gestão de Projetos pela Universidade Norte do Paraná (UNOPAR). Pós-Graduado em Infraestrutura de Transportes e Rodovias pelo Instituto Brasileiro de Educação Continuada (INBEC). Tem experiência em engenharia de planejamento e controle de obras rodoviárias.

\section{Francisco Heber Lacerda de Oliveira}

Doutor em Engenharia de Transportes pelo Programa de Pós-Graduação em Engenharia de Transportes da Universidade Federal do Ceará. Professor adjunto do Departamento de Engenharia de Transportes da Universidade Federal do Ceará. Affiliate member in the American Society of Civil Engineers - ASCE. Tem experiência em planejamento do transporte aéreo, Operação, manutenção e reabilitação de infraestruturas aeroportuárias, especialmente em pavimentos de pátios e de pistas de pouso e decolagem.

Recebido em: 21.07.2019

Aceito em: 21.10.2019 